Disponível em

http://www.anpad.org.br/rac

RAC, Rio de Janeiro, v. 17, n. 2, art. 2,

pp. 154-175, Mar./Abr. 2013

$(\mathrm{cc})$ EY-NC

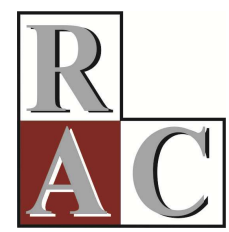

\title{
A Qualidade do Relacionamento com Marca e as Implicações sobre a Lealdade
}

\section{Brand Relationship Quality and the Implications for Loyalty}

Eliane Cristine Francisco-Maffezzolli

E-mail: eliane.francisco@pucpr.br

Pontifícia Universidade Católica do Paraná - PPAD/PUCPR

Rua Imaculada Conceição, 1155, Bl. Acadêmico, Sala 103B, Prado Velho, 80215-901, Curitiba, PR, Brasil.

Elder Semprebom

E-mail: adm.elder@gmail.com

Universidade Federal do Paraná - PPGADM /UFPR

Rua Prof. Lothário Meissner, 632, Jardim Botânico, 80210-170, Curitiba, PR, Brasil.

Paulo Henrique Muller Prado

E-mail: pprado@ufpr.br

Universidade Federal do Paraná - PPGADM /UFPR

Rua Prof. Lothário Meissner, 632, Jardim Botânico, 80210-170, Curitiba, PR, Brasil.

Clara Márcia Ribeiro

E-mail: clara.mkt@gmail.com Faculdade Pitágoras/Centro Universitário UNA Avenida Tom Jobim, 2890, Cidade Industrial, 32210-190, Contagem, MG, Brasil.

Artigo recebido em 23.11.2011. Última versão recebida em 10.09.2012. Aprovado em 13.09.2012. 


\title{
Resumo
}

O objetivo deste estudo é contribuir para o desenvolvimento da literatura de relacionamento com marcas por meio do teste de mensuração do construto, conhecido por Qualidade do Relacionamento com Marca (BRQ), testando a relação desta variável sobre a lealdade, tida como um dos resultados mais relevantes na estrutura de relacionamento. Um survey com 508 casos, para tanto, foi conduzido. Duas categorias de produto foram avaliadas: tênis esportivo e calça jeans. A análise foi realizada por meio de equações estruturais. Os resultados demonstram a validade do modelo de medida, além de constatar a relação positiva e significativa $(\beta=0,65$ / R2 $=43 \%$ ) entre o BRQ e a lealdade. Os achados agregam a esta relação uma reflexão sobre a categoria de produto e a diferença de gênero. O grupo feminino e os avaliadores da categoria de produto tênis esportivo indicaram, respectivamente, maior impacto sobre a lealdade e maior poder de explicação da relação testada. Tais resultados implicam em considerar que o êxito das estratégias de relacionamento com marcas pode estar atrelado às variáveis de gênero e categoria de produto, fato que sugere maior atenção dos gestores quanto às estratégias promocionais a serem adotadas.

Palavras-chave: qualidade do relacionamento com marca; lealdade; gêneros; categoria de produtos.

\begin{abstract}
The objective of this study was to contribute to the literature on brand relationship through the measurement of the construct known as Brand Relationship Quality (BRQ), and test the relationship this variable has with loyalty, regarded as one of the most relevant results to the relationship structure. A survey was conducted with 508 respondents. Two product categories were evaluated: sports shoes and jeans. The analysis was performed using structural equation modeling. The results demonstrate the validity of the measurement model, and emphasize the positive and significant relationship between BRQ and loyalty. The findings add to this relationship a reflection on product category and gender differences. The female group and evaluators of the sport shoes category showed, respectively, the greatest impact on loyalty and greater explanatory power of this relationship. These results imply that the success of a brand relationship strategy can be linked to the variables of gender and product category, which suggests greater management attention be paid to selecting promotional strategies.
\end{abstract}

Key words: brand-relationship quality; loyalty; gender; product category. 


\section{Introdução}

A preocupação em manter relações saudáveis e fortalecidas entre empresa e consumidor está alinhada com a evolução da concepção de marketing (Barnes, 2002). Esta tem por base a fonte de diferenciação e vantagem competitiva conforme a oferta de relacionamentos únicos sustentados por pilares como a confiança no parceiro e o comprometimento das partes na relação (Morgan \& Hunt, 1994), além da possibilidade de criação conjunta de valor (Grönroos, 1997). Somado a isto, para estratégias defensivas sobre bases de receita de uma empresa, A. Fornell (1992) ressalta dois caminhos: (a) aumentar o nível de satisfação e (b) criar barreiras de troca. Neste caso, a busca por excelência de produtos e serviços e satisfação do consumidor data de meados da década de 60 (Oliver, 1981). Já no que tange à criação de barreiras de troca, inúmeras situações podem oferecer subsídios para esta situação, como a exclusividade ou a compatibilidade de produtos e serviços (Grönroos, 1997), a força e poder da marca (Kapferer, 2003), o atendimento ou demais pontos de contato da empresa com o consumidor (Zeithaml, 1988), entre outros. Neste contexto, é possível perceber o valor conceitual e prático da qualidade do relacionamento em uma relação comercial.

Na década de 1990, Fournier (1998) expandiu a perspectiva de análise e acresceu a presença da marca nas avaliações de relacionamento. Para tanto, a autora fez uso de teorias de relacionamento pessoal e propôs um modelo conceitual chamado de Brand Relationship Quality (BRQ), no qual destacou três tipos de ligações: (a) Ligações afetivas e socioemotivas (amor/paixão e autoconexão); (b) Ligações comportamentais (interdependência e comprometimento); e (c) Ligações cognitivas (intimidade e parceria). Em 2000, a autora apresentou uma proposta de mensuração do modelo, mas com alguns gaps, como a junção operacional entre amor e comprometimento, bem como separação da variável intimidade em termos da avaliação consumidor $\mathrm{x}$ empresa e empresa $\mathrm{x}$ consumidor (Fournier, 2009). Tais gaps incitam o desenvolvimento de instrumentos de medida que sejam mais fiéis à proposta original e que mantenham, na íntegra, a particularidade de cada variável envolvida no modelo. O BRQ, em sua essência, reflete a capacidade da marca manter uma relação com o consumidor por meio do compartilhamento de significados acerca da marca e da experiência do consumidor.

Ressalta-se ainda que a manifestação do BRQ não é evidente e visível em uma primeira análise entre consumidores. Por exemplo, não se trata apenas da recompra, mas, sim, de investigar as razões de consumo de determinada marca considerando o compartilhamento de valor, identidade e imagem da marca (Keller \& Machado, 2006; Reimann \& Aron, 2009). Neste caso, agrega-se valor à percepção e à experiência do consumidor com a marca como elemento fundamental do BRQ em resposta à oferta de uma determinada no mercado (Ashworth, Dacin, \& Thomson, 2009).

Por fim, tem-se que para o indivíduo/consumidor os relacionamentos são constituídos porque estão apoiados em alguma finalidade e/ou função como as questões utilitárias, emocionais/hedônicas, expressivas de valor, de afiliação, inserção social e/ou de estabilidade/conforto social (Ashworth et al., 2009). Ressalta-se, neste contexto, que estas funções são obtidas pelo contato e uso contínuo da marca e, portanto, estão associadas à manifestação de um comportamento leal.

Desta forma, clarifica-se que o propósito deste estudo é verificar a relação da qualidade do relacionamento com marca sobre a lealdade do consumidor. Nesse sentido, três outros produtos do estudo são explorados: (a) a validação de um modelo de mensuração da qualidade do relacionamento com marca - BRQ; (b) a verificação da estrutura refletiva do BRQ sobre os construtos que o compõem, e (c) a verificação da relação do BRQ sobre a lealdade e das possíveis variáveis categóricas que interferem este processo de avaliação. 


\section{Referencial Teórico}

O referencial teórico deste estudo está estruturado em duas partes: a primeira trata dos construtos que compõem a qualidade do relacionamento com marcas e as respectivas proposições de pesquisa sobre esta relação refletiva. A segunda parte trata da lealdade como um dos elementos de consequência deste modelo de avaliação e apresenta a hipótese relacionada a esta situação.

\section{Qualidade do relacionamento com marca}

A proposta original do modelo chamado de Brand Relationship Quality (BRQ) foi elaborado por Fournier (1998). São destacados três tipos de ligações neste modelo, sendo elas: (a) afetivas e socioemotivas (amor/paixão e autoconexão); (b) comportamentais (interdependência e comprometimento); e (c) cognitivas (intimidade e parceria).

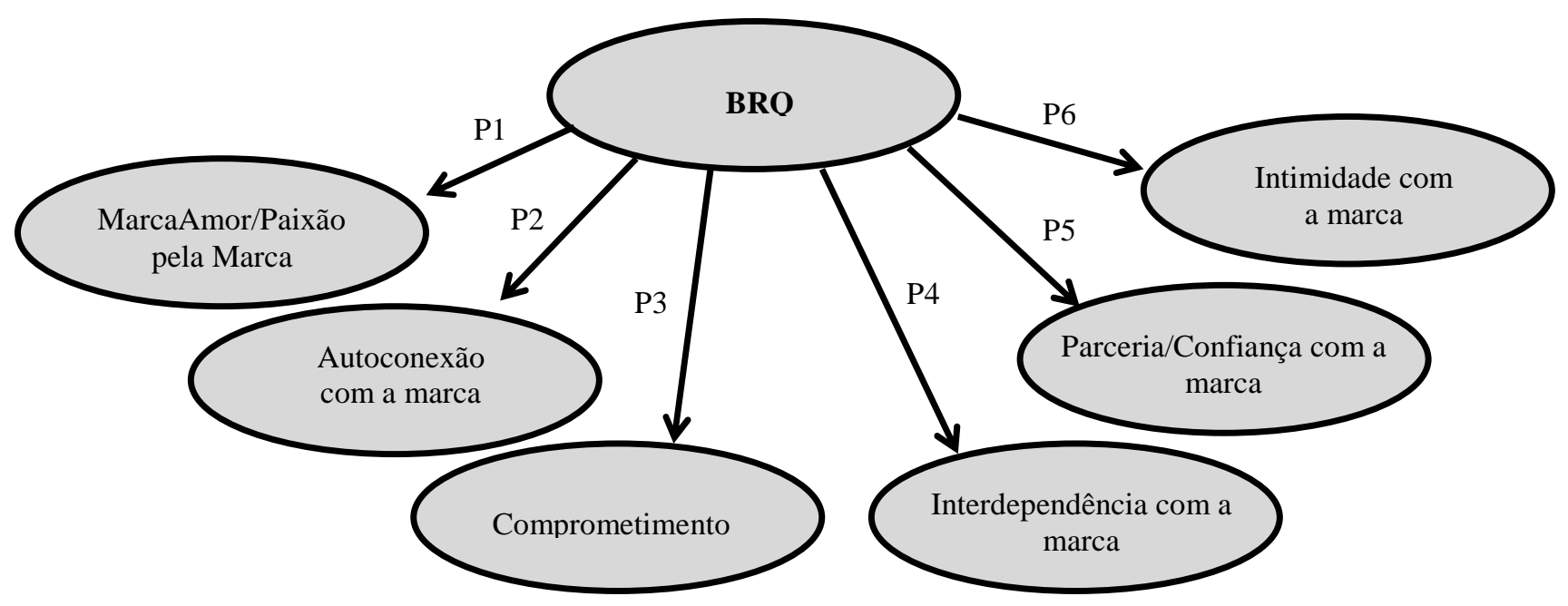

Figura 1. Modelo Conceitual e Proposições do Modelo de Mensuração.

Fonte: Adaptado de Fournier, S. (1998). Consumers and their brands: developing relationship theory in consumer research (p. 366). Journal of Consumer Research, 24(4), 343-353. doi: 10.1086/209515

A Figura 1 ilustra o modelo teórico do BRQ de acordo com o estudo original proposto por Fournier (1998) e sugere estrutura refletiva (Bisbe, Batista-Foguet, \& Chenhall, 2007) na composição do modelo de mensuração. Também são demonstradas, na figura 1, as proposições de pesquisa (p) em relação à estrutura do $\mathrm{BRQ}$. A revisão de literatura segue com foco em cada uma das variáveis latentes do BRQ, bem como na apresentação das proposições de pesquisa.

\section{Ligações afetivas e socioemotivas}

O amor/paixão pela marca corresponde à capacidade do indivíduo dedicar a uma determinada marca forte ligação afetiva positiva. Isso implica na sensação de bem-estar e preferência pelo uso da marca (Fournier, 1998). Este construto pode ser suportado pela literatura acerca dos sentimentos. Segundo Frijda, Manstead e Bem (2000), sentimentos são considerados disposições emocionais duradouras, que estão relacionadas à estrutura de distribuição da cognição, ou seja, à distribuição social, à externalização e à distribuição temporal. Ainda segundo os autores, esta manifestação positiva pode orientar a pessoa para o curso de suas atitudes ou crenças.

Outra perspectiva está apoiada na teoria do apego conforme estudo de Schouten e McAlexander (1995). Os autores analisam o desenvolvimento do apego com marcas no caso dos New bikers. Também Ahuvia (2005) demonstra, via investigação qualitativa, a possibilidade dos objetos amados (extensível às marcas) simbolizarem algo relevante para o indivíduo que o detém, a ponto do uso de 
determinado produto/marca ser designado como forte e intenso desejo, seguido de satisfação, alegria, amor, entre outras possíveis ligações positivas que podem ser desencadeadas. Neste caso, segue apresentada a proposição (p) 1:

p1: o Amor/Paixão por uma marca reflete de forma positiva e significativa parte da qualidade do relacionamento com marca.

Entretanto cabe ressaltar que a teoria sobre sentimentos e emoções traz muitas controvérsias desde sua concepção e forma de mensuração. Desta forma, sugere-se uma simplificação deste constructo para que seja possível a inclusão e mensuração deste item no BRQ. Para tanto, o estudo empírico a ser apresentado fez uso apenas de algumas expressões positivas para designar parte da percepção da relação entre consumidor e marca consumida. A escala foi adaptada de Prado (2004).

A autoconexão com a marca compreende o grau com que o relacionamento com a marca ajuda a expressar seus conceitos reais, desejados, ou coletivos, indicando a ativação de um sistema de conexão pessoal (Fournier, 1998). Esta variável está associada à literatura de relacionamentos íntimos e incita a investigação da perspectiva dos estilos de conexão (attachment styles), os quais estão relacionados à natureza do relacionamento e à história que o consumidor pode ter com a marca (Hazan \& Shaver, 1994). Portanto, credita-se a este construto a condição de suporte oferecido pela marca na expressão de sua imagem do indivíduo (Fournier, 1998, 2009; Francisco-Maffezzolli, Prado, \& Montaña, 2010).

Escalas e Bettman (2009) acrescentam ainda o poder de compartilhamento de significado entre a identidade e a imagem da marca, considerando os estímulos promocionais gerados pelo fabricante, pela mídia e pelo meio social. Sendo assim, a autoconexão com a marca passa a ser um vínculo emocional/afetivo entre o consumidor e a marca, tendo em vista aspectos de congruência (por exemplo: de imagem) entre as partes. Portanto acredita-se que quanto mais forte e positiva seja esta relação, maior será o reflexo no BRQ, conforme a proposição 2:

p2: a Autoconexão com a marca reflete de forma positiva e significativa parte da qualidade do relacionamento com marca.

\section{Ligações comportamentais}

A estrutura de relacionamento não é definida apenas por questões emocionais/afetivas. Sendo assim, como parte das ligações comportamentais, vinculadas aos hábitos, rotinas e ações do consumidor, está o comprometimento com a marca.

O comprometimento com a marca é definido pelo desejo em manter a continuidade em um relacionamento (Wilson, 1995). Morgan e Hunt (1994) agregam a condição do esforço empreendido para manter-se um relacionamento pelas partes envolvidas. Prado (2004) ressalta que a manifestação desta variável pode ser mensurada com diferentes dimensões, dentre elas: afetiva, instrumental e calculativa. Em especial, a questão afetiva está associada ao desejo de manter o relacionamento devido à sensação de bem-estar, de ser valorizado e respeitado pelo outro. Questões instrumentais estão ligadas a estímulos, prêmios e punições que podem ocorrer em uma relação. Já a esfera calculativa abarca benefícios financeiros e tangíveis.

Fournier (1998) atribui a esta variável a percepção que o consumidor pode ter sobre uma marca enquanto elemento de manutenção do status quo. O comprometimento com uma marca aumenta na medida em que a pessoa a valora como item imprescindível para manter sua integridade e/ou externalizar uma certa característica no meio social. Este constructo também está apoiado nas teorias de relacionamento humano interpessoal (Vala \& Monteiro, 2004) e deve aumentar o nível de qualidade do relacionamento com a marca, pois o desejo de manter a relação é encarado como benefício mútuo. Neste contexto é apresentada a proposição 3. 
p3: o comprometimento com a marca reflete de forma positiva e significativa parte da qualidade do relacionamento com marca.

Como outra ligação comportamental, a interdependência com a marca é definida pela sensação de dependência mútua entre as partes envolvidas em uma relação (Prado et al., 2009). Este construto está apoiado na teoria da interdependência (Thibault \& Kelley, 1959), e busca compreender o relacionamento entre os membros do grupo. Rusbult e Arriaga (1997) definem a interdependência como a forma e o grau nos quais indivíduos interagem ou influenciam a experiência de outros. A origem deste construto como parte do BRQ esteve apoiada no estudo fenomenológico realizado por Fournier (1998). Com suporte nos relatos das entrevistadas, a autora percebeu o vinculo simbólico criado entre as respondentes e certos produtos/marcas, dado suas respectivas rotinas, hábitos preferências e motivações de uso. Desde então, outros autores buscaram compreender esta relação de dependência em estudos qualitativos (Francisco-Maffezzolli et al., 2008) e quantitativos (Prado et al., 2009). Neste sentido segue a proposição 4 deste estudo:

p4: a interdependência com marca reflete de forma positiva e significativa parte da qualidade do relacionamento com marca

\section{Ligações cognitivas}

Entre as ligações cognitivas destacadas por Fournier (1998), a parceria com a marca, ou qualidade da parceria (original partner quality), indica a confiança mútua das partes envolvidas em uma relação (Garbarino \& Johnson, 1999; Grönroos, 1990). Morgan e Hunt (1994) apresentam esta variável como mediadora entre os valores da empresa e a comunicação realizada a fim de disseminar a identidade pretendida da marca no mercado. Apesar do trabalho dos autores estar focado em B2B o princípio de credibilidade permanece o mesmo, independente do perfil das partes envolvidas.

Este senso de parceria também evoca a percepção da marca como "parceira", como o nome sugere, para as atividades rotineiras como correr no parque. Isso implica no conforto e segurança do consumidor sobre ter realizado uma boa escolha e poder "contar com a marca quando precisa" (Fournier, 1998). Park, Mackinnis e Priester (2009) destacam a parceira/senso de confiança em uma marca como base do relacionamento, pois, sem o compartilhamento e a crença dos valores de uma determinada marca, esta é percebida como frágil e de baixa preferência. Neste caso, a experiência do consumidor e a finalidade do uso da marca são elementos importantes para a compreensão deste fenômeno. Portanto, a proposição 5 reforça a importância deste construto na avaliação do BRQ.

p5: o senso de parceria com marca reflete de forma positiva e significativa parte da qualidade do relacionamento com marca.

Por fim, mas não menos importante, a intimidade com a marca trata do outro elemento cognitivo sugerido por Fournier (1998). Proveniente da literatura de relacionamentos íntimos, a autora define que esta variável refere-se a uma sensação de compreensão recíproca entre companheiros de relacionamento. Ademais, este conceito também evoca esferas de conhecimento, vivência, experiência e familiaridade com a marca (Fournier, 1998; Ribeiro et al., 2010). Portanto é passível compreender que quanto maior a percepção de intimidade maior deve ser o reflexo na avaliação na qualidade do relacionamento com marca:

p6: a intimidade com a marca reflete de forma positiva e significativa parte da qualidade do relacionamento com marca.

\section{Qualidade do relacionamento com a marca e a lealdade}

Ashworth, Dacin e Thomson (2009) propõem a compreensão das motivações acerca dos relacionamentos com marca. De acordo com os autores, alguns questionamentos são relevantes (e provocativos) para o desenvolvimento desta área de pesquisa: por que pessoas e marcas buscam manter um relacionamento? Quais são os benefícios para as partes envolvidas? De acordo com os 
autores, para o indivíduo consumidor, a experiência com a marca e o compartilhamento de informações no meio social acerca dos valores, imagem e diferenciais da marca, pode desencadear o processo de identificação com esta. Portanto, para o consumidor, o relacionamento pode ser iniciado e mantido quando a vantagem simbólica é acionada, ou seja, quando o uso de uma determinada marca permite o reforço da imagem real ou desejada de si mesmo perante a comunidade. Esta proposição está alinhada ao trabalho de Tildesley e Coote (2009) em relação ao efeito de identificação com a marca.

No entanto, conforme comentado anteriormente, outros resultados são esperados do relacionamento com marcas. O estudo realizado por Ashworth et al. (2009) aponta 6 dimensões de benefícios/funções percebidas pelo consumidor: (a) reforço social, (b) benefício utilitário, (c) hedônico, (d) expressivo de valor, (e) poder de afiliação e (f) conhecimento/conforto social. Já para a marca, ou melhor, para os gestores de marca, alguns benefícios foram identificados, como qualidade percebida, atitude favorável em relação à marca, boca a boca positivo, predisposição para defesa da marca e percepção de responsabilidade social. Tais ações estão associadas à lealdade manifestada na relação.

Desse modo as motivações que impactam no resultado do relacionamento sugerem a reflexão da importância da lealdade na relação. Este conceito é investigado na literatura de marketing de relacionamento desde a década de 1970 (Yi \& Jeon, 2003) e é definido pela crença de que o fornecedor/marca representa a melhor opção alternativa a ser consumida (Oliver, 1999). No entanto cabe ressaltar que esta variável representa não apenas o índice de recompra, mas, sim, outros aspectos simbólicos, atitudes e comportamentos. Por exemplo a intenção de continuidade, a capacidade de recomendar e a percepção da marca como melhor opção entre as demais correntes. Tal forma de conceber a essência da lealdade permite evitar as situações falsas como o comportamento por inércia, rotinas, falta de informação ou conhecimento do mercado, entre outros (Tam, Wood, \& Ji, 2009).

Neste contexto, o presente estudo fez uso da variável lealdade como um dos elementos representantes e resultantes dos benefícios percebidos no relacionamento com marcas. Esta relação já foi pontuada por outros autores (Fournier, 1998; Goodstein \& Butz, 1998; Jones \& Sasser, 1995; Mackinnis, Priester, \& Parker, 2009), fato que permite a validação de critério da relação e é base da hipótese 1:

h1: o BRQ impacta a lealdade de forma positiva e significativa.

$\mathrm{Na}$ sequência é apresentado o procedimento metodológico do estudo empírico e os principais resultados obtidos.

\section{Metodologia}

A pesquisa empírica deste estudo é caracterizada como quantitativa, descritiva e transversal única (Malhotra, 2006). Para seu desenvolvimento, foi conduzido um survey com aplicação presencial em sala de aula, totalizando 508 casos, sendo a amostra composta por jovens universitários de Curitiba, com idade de 18 a 30 anos (52,8\% do sexo feminino), consumidores de calça jeans e tênis esportivo. Como critério de filtro do estudo, os respondentes deveriam ter pelo menos 3 produtos da marca escolhida por eles na hora da pesquisa, visto que a avaliação das marcas citadas dependia da estrutura de relacionamento implícita nas escolhas de consumo. Em estudos anteriores, os autores desenvolveram separadamente as escalas dos construtos que compõem o modelo de pesquisa proposto neste estudo (Francisco-Maffezzolli et al., 2010; Prado et al., 2009; Ribeiro et al., 2010). De acordo com os objetivos propostos pelo estudo, um aspecto original a este estudo foi o teste do modelo proposto por Fournier (1998), com escalas criadas especificamente para o contexto de relacionamento em relação à lealdade declarada pelo consumidor. A Tabela 1 relaciona as escalas utilizadas. 
Tabela 1

Definição Operacional dos Construtos

\begin{tabular}{lll}
\hline Construto & Dimensionalidade & Origem da Escala \\
\hline Amor/Paixão pela marca & Unidimensional (4 itens) & Adaptado de Prado (2004) \\
Autoconexão com a marca & Bidimensional (8 itens) & Francisco-Maffezzolli et al. (2010) \\
Comprometimento & Multidimensional (16 itens) & Prado (2004) \\
Interdependência com a marca & Unidimensional (6 itens) & Prado et al. (2009) \\
Parceria/Confiança na marca & Unidimensional (4 itens) & Adaptado de Prado (2004) \\
Intimidade com a marca & Bidimensional (12 itens) & Ribeiro et al. (2010) \\
Lealdade com a marca & Unidimensional (6 itens) & Adaptado de Prado (2004) \\
\hline
\end{tabular}

Nota. Fonte: Resultado da pesquisa. I representa o número de indicadores de cada construto. Foram utilizadas escalas intervalares de concordância com 10 pontos.

A unidade de análise foi definida pelo consumidor (pessoa física) que estivesse enquadrado nos padrões definidos no filtro da pesquisa. O processo de análise dos dados iniciou com a análise descritiva dos dados, seguida de Análise Fatorial Exploratória para cada variável analisada e Teste de Alpha de Cronbach. Na sequência, tendo em vista as proposições de pesquisa sobre a característica refletiva do modelo BRQ, foi verificada a Análise Fatorial Confirmatória, enquanto modelo de mensuração do BRQ. Assim, foram considerados os índices de ajuste do modelo proposto, bem como o peso e a significância das relações propostas. Posteriormente, foi testada a hipótese de pesquisa via modelagem estrutural para compreender o impacto do BRQ sobre a lealdade. Por fim, o modelo foi comparado por meio de segmentação da base, de acordo com o gênero dos respondentes e a categoria de produto (tênis esportivo e calça jeans).

\section{Análise dos Resultados}

A análise dos resultados está organizada em duas seções: a primeira dedica-se à análise e validade do modelo de mensuração, visto que o uso conjunto das escalas propostas para cada construto do BRQ é parte da contribuição do artigo, tendo em vista sua característica latente. A segunda parte apresenta a relação estrutural do BRQ com a lealdade, bem como explora caminhos para compreender outros elementos que podem intervir no processo de avaliação do relacionamento com marcas, como o gênero e a categoria de produto.

\section{Avaliação do modelo de mensuração}

Para uma breve compreensão da base de respondentes, foram consideradas 508 respostas válidas, sendo $54 \%$ mulheres e $46 \%$ homens, $40 \%$ dos casos responderam sobre marcas de tênis esportivo e $60 \%$ sobre marcas de calça jeans. A faixa etária predominante, $83 \%$, foi de respondentes entre 20 e 25 anos, $86 \%$ solteiros; em que $92 \%$ registram nível de instrução entre médio completo e superior incompleto. O estudo foi realizado na cidade de Curitiba, no Paraná. O método de extração escolhido foi a análise de componentes principais. De acordo com Malhotra (2012), este método é recomendado quando a preocupação maior está em determinar o número mínimo de fatores que respondam pela máxima variância nos dados para utilização de análises multivariadas subsequentes, como será visto adiante.

Conforme apresentado na Tabela 2, os resultados descritivos iniciais demonstram adequação das variáveis latentes utilizadas no que tange aos aspectos de dimensionalidade e confiabilidade. Nesse 
sentido, percebe-se que os índices de KMO estão em valores adequados e significativos, conforme critério adotado por Pallant (2001) (>0,7), bem como as porcentagens de variância explicada em cada variável latente. Dos seis construtos, todos registraram valores acima de 50\%, sendo 4 acima de 66\%. Isto implica na capacidade do BRQ ser, de fato, uma estrutura de terceira ordem refletida pelas seis variáveis latentes propostas, de acordo com a dimensionalidade de cada construto. Como critério de confiabilidade da escala foi utilizado o valor do Alpha de Cronbach. Todos os construtos registraram valores acima de 0,6, como padrão de qualidade mínima exigido por Churchill (1987).

Ao analisar as médias e desvio padrão, percebe-se que os índices de maior concordância (valores médios acima de 6,0) foram registrados nos itens de interdependência, parceria e autoconexão na dimensão de estima. Isto implica em reconhecer que, embora as escalas estejam adequadas ao estudo, nem todas as marcas pesquisadas demonstram a percepção de um relacionamento forte $\mathrm{e}$ intenso. Tal situação é resultante de dois fatores: (a) a escolha da categoria de produtos em análise e (b) a multiplicidade de marcas avaliadas. Para tênis esportivo, mais de 30 marcas foram registradas na avaliação. Já para calça jeans, mais de 40 marcas forma indicadas.

Tabela 2

\section{Resumo Descritivo das Escalas em Estudo}

\begin{tabular}{|c|c|c|c|c|c|c|}
\hline & Indicadores & Média (dp) & KMO & Loading & VE & Alpha \\
\hline \multirow{5}{*}{ 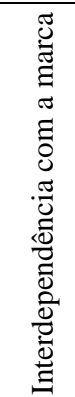 } & $\begin{array}{l}\text { 1. Ao compará-la com as demais marcas, ainda tenho } \\
\text { preferência pela Marca X. }\end{array}$ & $7,4(2,0)$ & \multirow{5}{*}{0,784} & 0,805 & \multirow{5}{*}{$54,80 \%$} & \multirow{5}{*}{0,792} \\
\hline & 2. Não tenho a intenção de trocar a Marca X. & $5,8(2,4)$ & & 0,805 & & \\
\hline & 1. A Marca X possui características que são únicas. & $6,4(2,3)$ & & 0,752 & & \\
\hline & $\begin{array}{l}\text { 4. Pelas vantagens que a Marca } X \text { me proporciona ela é } \\
\text { importante para mim. }\end{array}$ & $6,3(2,2)$ & & 0,687 & & \\
\hline & $\begin{array}{l}\text { 5. Pelas vantagens que a Marca X me proporciona sinto-me } \\
\text { dependente a ela. }\end{array}$ & $3,3(2,2)$ & & 0,637 & & \\
\hline \multirow{6}{*}{ 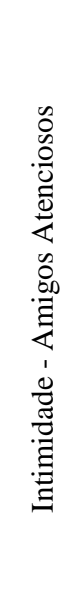 } & $\begin{array}{l}\text { 1. A marca } \mathrm{x} \text { dedica tempo ouvindo as minhas necessidades } \\
\text { para desenvolver o produto mais adequado pra mim. }\end{array}$ & $4,0(2,2)$ & & 0,776 & & \multirow{7}{*}{0,838} \\
\hline & $\begin{array}{l}\text { 2. A marca } x \text { sempre me dá a liberdade de expressar o que } \\
\text { eu quero. }\end{array}$ & $4,5(2,2)$ & & 0,71 & & \\
\hline & $\begin{array}{l}\text { 3. Eu faço sugestões construtivas à marca x para que ela } \\
\text { melhore seus produtos. }\end{array}$ & $3,2(2,1)$ & & 0,706 & & \\
\hline & $\begin{array}{l}\text { 4. A marca } \mathrm{x} \text { me encoraja a fazer parte do processo de } \\
\text { construção de seus produtos. }\end{array}$ & $3,2(2,1)$ & & 0,697 & & \\
\hline & $\begin{array}{l}\text { 5. A empresa fabricante da marca } \mathrm{x} \text { sempre me mantém } \\
\text { informada de seus novos desenvolvimentos/produtos. }\end{array}$ & $5,4(2,8)$ & & 0,673 & & \\
\hline & $\begin{array}{l}\text { 6. Consigo me comunicar com a empresa que fabrica a } \\
\text { marca x sempre que }\end{array}$ & $4,1(2,2)$ & 0,899 & 0,652 & $55,50 \%$ & \\
\hline \multirow{6}{*}{ 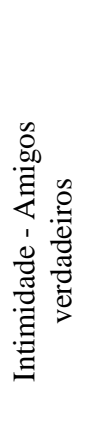 } & Tenho acesso fácil às informações relativas à marca $\mathrm{x}$. & $6,5(2,3)$ & & 0,547 & & \\
\hline & $\begin{array}{l}\text { 1. Assim como eu me relaciono com a marca } \mathrm{x} \text {, sinto que } \\
\text { ela também se relaciona comigo. }\end{array}$ & $4,2(2,3)$ & & 0,778 & & \multirow{5}{*}{0,838} \\
\hline & 2. Me sinto próximo a marca $x$ & $5,3(2,2)$ & & 0,777 & & \\
\hline & 3. Tenho um grande conhecimento sobre a marca $\mathrm{x}$. & $5,1(2,3)$ & & 0,743 & & \\
\hline & $\begin{array}{l}\text { 4. A marca x está presente nos meus momentos mais } \\
\text { íntimos. }\end{array}$ & $4,1(2,4)$ & & 0,723 & & \\
\hline & $\begin{array}{l}\text { 5. A marca } x \text { me oferece fontes de apoio para o } \\
\text { desenvolvimento de nosso relacionamento. }\end{array}$ & $4,0(2,1)$ & & 0,693 & & \\
\hline
\end{tabular}


Tabela 2 (continuação)

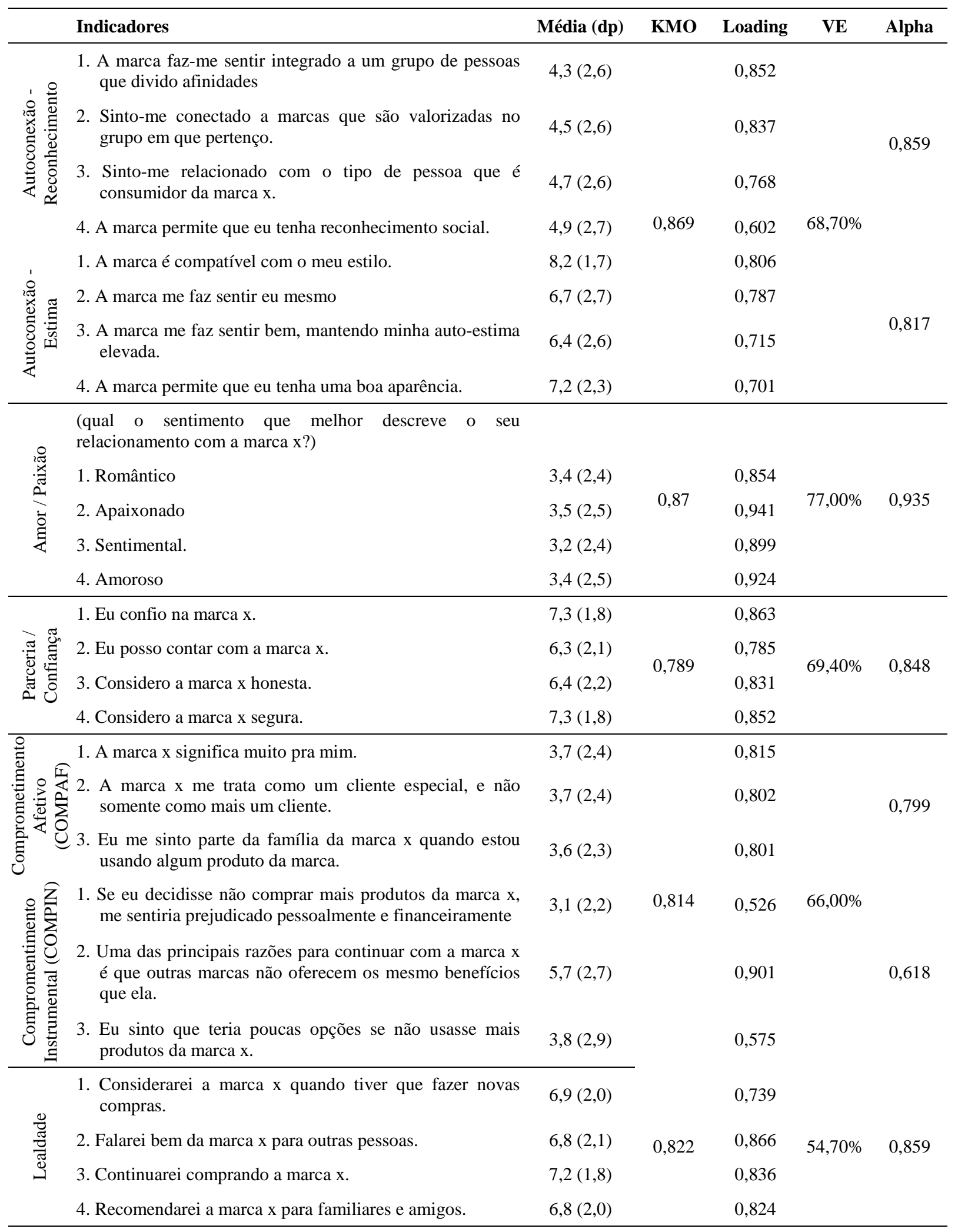

Recorda-se que o filtro da pesquisa era a experiência de uso da marca em relação ao número de peças da mesma marca (mínimo 3), sendo a última compra nos últimos 6 meses (a contar a data da realização da coleta de dados). Portanto a avaliação de marcas em categorias de envolvimento médio e a heterogeneidade das marcas pode ter influenciado na qualidade da avaliação. 
Sobre a composição conceitual de cada variável latente, a interdependência foi mensurada conforme sugestão de Prado et al. (2009), em termos do senso de dependência da marca em relação a tarefas e funções rotineiras. Isto foi evidenciado nas afirmações sobre a preferência pela marca, já que ela é importante e presente no dia a dia.

Já intimidade demonstrou ser uma variável latente multidimensional, tendo destaque para amigos verdadeiros (alpha 0,838 ), que explicita a proximidade da relação do consumidor e marca consumida e amigos atenciosos (alpha 0,838), apoiada no suporte de comunicação percebido na relação. Este resultado está próximo às definições conceituais tratadas sobre o tema, em especial, quanto ao conhecimento entre as partes, ao senso de reciprocidade, experiência e familiaridade (Fournier, 1998; Ribeiro et al., 2010). Ressalta-se que a escala evidencia ajuste e confiabilidade plausíveis, embora as avaliações médias demonstrem baixo incide de concordância (valores próximos entre 3 e 5) em relação às marcas e categorias avaliadas.

A autoconexão com a marca também apontou característica bidimensional: (a) estima (alpha 0,817) e (b) reconhecimento (alpha 0,859). Isso implica em conceber que o nível de conexão com a marca pode ocorrer em ordem pessoal/individual e por fonte social, ou seja, pelo reforço e identificação com o meio social que o uso da marca pode proporcionar, como previsto por Escalas e Bettman (2009).

O nível de amor/paixão sentido por uma marca demonstrou adequada composição na escala (alpha 0,935), mas baixo índice de média (valores médios de 3,5 com dp de aproximadamente 2,5). Novamente, implicando em reconhecer que, embora o instrumento de coleta seja apropriado, as marcas avaliadas, na média, não representam uma relação de amor profunda.

A percepção de parceira/confiança na marca, além de médias mais positivas (valores entre 6 e 7), revelam boa confiabilidade (alpha de 0,848) e variância explicada de 69\%. Este fato está alinhado ao conceito do construto, o qual reforça a crença de uma relação segura, estável e confiável (Fournier, 1998; Garbarino \& Johnson, 1999; Grönroos, 1990). Por fim, o comprometimento foi avaliado de forma bidimensional, tendo destaque para: (a) comprometimento afetivo (COMPAF) e (b) comprometimento instrumental/de continuidade (COMPIN), conforme sugestão inicial da escala utilizada de Prado (2004). Este construto apresentou o índice mais tênue de confiabilidade na dimensão instrumental (alpha de 0,618), em termos do valor mínimo ideal (Churchill, 1987). A primeira, COMPAF, está apoiada na sensação afetiva sobre o indivíduo sentir-se parte da família da marca e ser um cliente especial. A segunda está apoiada em benefícios instrumentais recebidos por consumir uma determinada marca, visto que esta é considerada única e especial. Sugere-se que, na relação de qualidade do relacionamento, esta dimensão contribua com o menor peso, pois se trata de uma perspectiva mais racionalizada do comprometimento. Também foi analisada a consistência da variável dependente do modelo. A lealdade com a marca registrou médias altas (acima de 6) e bom índice de consistência interna (alpha de 0,859). De acordo com a escala original (Prado, 2004), dois indicadores foram excluídos no intuito de melhor consistência sem, no entanto, perda de conteúdo.

Como análise adicional do conjunto destas variáveis latentes foi realizada uma Análise Fatorial Confirmatória, com o método de estimação Maximum Likelihood. A escolha deste método de estimação assume as condições exigidas por Byrne (2001), cuja amostra tem um número de casos considerado elevado $(n=508)$, o modelo hipotético é válido e a escala de mensuração é contínua. A CFA foi conduzida considerando a dimensionalidade dos construtos. Conforme Anderson e Gerbering (1988), este método é um dos mais indicados para teste e desenvolvimento de teoria. Além disto, métodos que utilizam a informação completa proveem parâmetros de estimação que melhor explicam as covariâncias observadas. O resultado demonstrou índices de ajuste aceitáveis (Hair, Anderson, Tatham, \& Black, 2005): CMIN/DF 2,078, NFI = 0,882, RFI = 0,868, IFI $=0,935$, TLI $=0,0,927$, CFI $=0,935$ e RMSEA $=0,046$. De acordo com o critério de Hair, Anderson, Tatham e Black. (2005), os índices são aceitáveis, pois CMIN/DF deve ser inferior a 5, e as demais medidas de qualidade de ajuste (NFI, RFI, IFI, TLI e CFI) devem ser superior a 0,9. Para os autores, também, é adequado que o RMSEA seja inferior a 0,08 . Os resultados obtidos estão muito próximos do ideal. A Tabela 3 ilustra índices complementares de avaliação da CFA como os pesos, o valor da AVE e a Confiabilidade Composta. Para o processo de CFA, a dimensão comprometimento instrumental foi retirada do 
modelo devido à sua baixa contribuição na explicação. Fournier (2009) indicou o caminho afetivo do comprometimento como item fundamental na relação de qualidade do relacionamento, pois considera que benefícios instrumentais podem racionalizar demasiadamente uma relação de origem afetiva. De fato, o modelo proposto neste estudo diz respeito ao relacionamento muito mais afetivo do que instrumental entre consumidores e marcas. Desta forma, mesmo com a exclusão desta informação, o conteúdo mais relevante que indica o comprometimento afetivo foi mantido.

Tabela 3

\section{Índices Complementares de Avaliação da CFA}

\begin{tabular}{|c|c|c|c|c|}
\hline Indicador & Variável & Load & $\mathbf{C C}$ & AVE \\
\hline Pelas vantagens ... sinto-me dependente a ela. & \multirow{4}{*}{ Interdependência } & 0,59 & \multirow{4}{*}{0,78} & \multirow{4}{*}{0,47} \\
\hline Pelas vantagens ... ela é importante para mim. & & 0,82 & & \\
\hline A Marca X possui características que são únicas. & & 0,64 & & \\
\hline Não tenho a intenção de trocar a Marca X. & & 0,67 & & \\
\hline A marca $\mathrm{x}$ dedica tempo ouvindo as minhas necessidades... & \multirow{5}{*}{$\begin{array}{l}\text { Intimidade - Amigos } \\
\text { Atenciosos }\end{array}$} & 0,67 & \multirow{5}{*}{0,83} & \multirow{5}{*}{0,49} \\
\hline $\begin{array}{l}\text { A marca x sempre me dá a liberdade de expressar o que eu } \\
\text { quero. }\end{array}$ & & 0,76 & & \\
\hline $\begin{array}{l}\text { Eu faço sugestões construtivas à marca x para que ela } \\
\text { melhore... }\end{array}$ & & 0,69 & & \\
\hline $\begin{array}{l}\text { A marca } x \text { me encoraja a fazer parte do processo de } \\
\text { construção... }\end{array}$ & & 0,73 & & \\
\hline $\begin{array}{l}\text { A empresa fabricante da marca } x \text { sempre me mantém } \\
\text { informada... }\end{array}$ & & 0,65 & & \\
\hline
\end{tabular}

A marca $x$ me oferece fontes de apoio para $o$ desenvolvimento...

A marca $\mathrm{x}$ está presente nos meus momentos mais íntimos.

Tenho um grande conhecimento sobre a marca $\mathrm{x}$.

0,67

Me sinto próximo a marca $\mathrm{x}$.

Verdadeiros

$0,67 \quad 0,84 \quad 0,51$

Assim como eu me relaciono com a marca $\mathrm{x}, \ldots$

0,74

A marca faz-me sentir integrado a um grupo de pessoas que divido...

Sinto-me conectado a marcas que são valorizadas no grupo...

Sinto-me relacionado com o tipo de pessoa que é consumidor da marca $\mathrm{x}$.

0,87

A marca permite que eu tenha reconhecimento social.

0,89

$\begin{array}{cccc}\begin{array}{ccc}\text { Autoconexão } \\ \text { Reconhecimento }\end{array} & 0,89 & 0,87 & 0,63 \\ & 0,73 & & \end{array}$

A marca permite que eu tenha uma boa aparência 0,66

A marca me faz sentir bem, mantendo minha auto-estima elevada

0,75

$0,83 \quad 0,55$

A marca me faz sentir eu mesmo

0,80

A marca é compatível com o meu estilo

0,73

Continua 


\section{Tabela 3 (continuação)}

\begin{tabular}{|c|c|c|c|c|}
\hline Indicador & Variável & Load & $\mathrm{CC}$ & AVE \\
\hline Romântico & \multirow{4}{*}{ Amor / Paixão } & 0,79 & \multirow{4}{*}{0,94} & \multirow{4}{*}{0,79} \\
\hline Apaixonado & & 0,94 & & \\
\hline Sentimental & & 0,91 & & \\
\hline Amoroso & & 0,92 & & \\
\hline Considero a marca $\mathrm{x}$ segura & \multirow{4}{*}{ Parceria / Confiança } & 0,81 & \multirow{4}{*}{0,85} & \multirow{4}{*}{0,60} \\
\hline Considero a marca $\mathrm{x}$ honesta. & & 0,77 & & \\
\hline Eu posso contar com a marca $\mathrm{x}$. & & 0,70 & & \\
\hline Eu confio na marca $x$ & & 0,81 & & \\
\hline A marca $\mathrm{x}$ significa muito pra mim. & \multirow{3}{*}{$\begin{array}{c}\text { Comprometimento } \\
\text { Afetivo }\end{array}$} & 0,81 & \multirow{3}{*}{0,80} & \multirow{3}{*}{0,58} \\
\hline A marca x me trata como um cliente especial... & & & & \\
\hline $\begin{array}{l}\text { Eu me sinto parte da família da marca } x \text { quando estou } \\
\text { usando... }\end{array}$ & & 0,72 & & \\
\hline Recomendar a marca $\mathrm{x}$ para familiares e amigos & \multirow{4}{*}{ Lealdade } & 0,81 & \multirow{4}{*}{0,86} & \multirow{4}{*}{0,61} \\
\hline Continuar comprando marca $\mathrm{x}$ & & 0,79 & & \\
\hline Falar bem da marca $\mathrm{x}$ para outras pessoas & & 0,85 & & \\
\hline $\begin{array}{l}\text { Considerar a marca } \mathrm{x} \text { quando tiver que fazer uma outra } \\
\text { compra. }\end{array}$ & & 0,66 & & \\
\hline
\end{tabular}

Espera-se que estas variáveis latentes, analisadas conjuntamente, possam refletir a qualidade do relacionamento com marca, bem como demonstrem a melhor compreensão sobre o efeito do BRQ no tocante à lealdade à marca. Desta forma, sugere-se que o valor atribuído pelo indivíduo para o senso de dependência na relação com a marca, para a intimidade desenvolvida na relação, para o nível de conexão com a marca, para o senso de parceria e comprometimento na relação com a marca e para percepção de amor ou forte (e positivo) sentimento pela marca, reflete o nível de qualidade do relacionamento com marca, bem como a propensão à lealdade. Ressalta-se que a etapa final de validação da CFA e teste do modelo registrou a supressão de alguns indicadores para fins de melhor ajuste do modelo. Ao todo, foram 6 indicadores removidos desde a análise da AFE e do alpha de Cronbach. É possível verificar os itens finais do modelo, conforme exposto na Tabela 3.

Como avaliação complementar para assegurar a validação discriminante de cada variável, a Tabela 4 elenca os valores das correlações, a variância média extraída (AVE), a confiabilidade composta e os quadrados das correlações das variáveis deste estudo. Este procedimento foi também utilizado por Carvalho-Freitas e Marques (2010). Como interpretação da tabela, na diagonal inferior, estão as correlações das variáveis latentes, já na diagonal superior, encontra-se o quadrado destas correlações. Na diagonal, estão os valores referentes à AVE. Conforme C. Fornell e Larcker (1981), espera-se que o quadrado das correlações seja inferior aos valores da AVE. Agrega-se a esta análise que o valor de referências das correlações deva ser inferior a 0,95 (Hair et al., 2005) para evitar índices de colinearidade. 
Tabela 4

Correlações* e Quadrado de Correlações entre as Variáveis em Teste

\begin{tabular}{lccccccccc}
\hline & LEALD & $\begin{array}{c}\text { COMP_ } \\
\text { AFET }\end{array}$ & $\begin{array}{c}\text { PAR/ } \\
\text { CONF }\end{array}$ & $\begin{array}{c}\text { AMOR_ } \\
\text { PAIXAO }\end{array}$ & $\begin{array}{c}\text { AC_ } \\
\text { EST }\end{array}$ & $\begin{array}{c}\text { AC_ } \\
\text { REC }\end{array}$ & $\begin{array}{c}\text { INTIM_ } \\
\text { AV }\end{array}$ & $\begin{array}{c}\text { INTIM_ } \\
\text { AA }\end{array}$ & INTER \\
\hline LEALD & $\mathbf{0 , 5 3 0}$ & 0,200 & 0,317 & 0,041 & 0,361 & 0,116 & 0,156 & 0,084 & 0,279 \\
COMP_AFET & 0,447 & $\mathbf{0 , 5 8 0}$ & 0,236 & 0,167 & 0,276 & 0,312 & 0,384 & 0,445 & 0,286 \\
PAR/CONF & 0,563 & 0,486 & $\mathbf{0 , 6 0 0}$ & 0,038 & 0,220 & 0,121 & 0,162 & 0,095 & 0,268 \\
AMOR_PAIXAO & 0,202 & 0,409 & 0,196 & $\mathbf{0 , 7 9 0}$ & 0,082 & 0,073 & 0,085 & 0,061 & 0,021 \\
AC_EST & 0,601 & 0,525 & 0,469 & 0,286 & $\mathbf{0 , 5 5 0}$ & 0,410 & 0,301 & 0,163 & 0,377 \\
AC_REC & 0,341 & 0,559 & 0,348 & 0,270 & 0,640 & $\mathbf{0 , 6 3 0}$ & 0,280 & 0,182 & 0,226 \\
INTIM_AV & 0,395 & 0,620 & 0,402 & 0,291 & 0,549 & 0,529 & $\mathbf{0 , 5 1 0}$ & 0,432 & 0,452 \\
INTIM_AA & 0,290 & 0,667 & 0,308 & 0,247 & 0,404 & 0,427 & 0,657 & $\mathbf{0 , 4 9 0}$ & 0,207 \\
INTER & 0,528 & 0,535 & 0,518 & 0,144 & 0,614 & 0,475 & 0,672 & 0,455 & $\mathbf{0 , 4 7 0}$ \\
\hline Confiabilidade & $\mathbf{0 , 8 4 0}$ & $\mathbf{0 , 8 0 0}$ & $\mathbf{0 , 8 5 0}$ & $\mathbf{0 , 9 4 0}$ & $\mathbf{0 , 8 3 0}$ & $\mathbf{0 , 8 7 0}$ & $\mathbf{0 , 8 4 0}$ & $\mathbf{0 , 8 3 0}$ & $\mathbf{0 , 7 8 0}$ \\
Composta & & & & & & & & &
\end{tabular}

Nota. Os valores em negrito, na diagonal, correspondem à AVE do construto. Os valores abaixo da diagonal representam as correlações encontradas no modelo. Os valores acima da diagonal representam o quadrado do coeficiente de correlação $\left(\mathrm{R}^{2}\right)$.

* todas as correlações são significativas a $p<0,05$.

Nestes resultados, além dos valores do BRQ também foi contrastada a lealdade, variável dependente do modelo proposto. De acordo com Hair et al. (2005), os valores obtidos são adequados, pois indicam correlação significativa e, ao mesmo tempo, valores inferiores a 0,65 . Este resultado sugere que os construtos analisados são, de fato, discriminantes entre si e fiéis ao conceito que cada um manifesta.

A avaliação conjunta destas variáveis latentes difere em alguns aspectos da proposta de Fournier (2009), mas registra maior congruência com a proposta original do modelo de BRQ. O presente estudo considera a particularidade conceitual da variável Amor/Paixão e sugere uma forma específica de medida com alpha de 0,935 e variância explicada de 77\%. Já Fournier (2009) trata da junção conceitual de amor e comprometimento. Entretanto a literatura define claramente cada variável sendo complementar entre si no BRQ e não como variáveis similares. As Tabelas 3 e 4 elencam os valores da correlação entre os construtos, além da confiabilidade composta e da variância média explicada de acordo com os resultados da CFA (Hair et al., 2005).

Além disso, Fournier (2009) atribui ao conceito intimidade dupla função: ao invés de considerar duas dimensões sobre o mesmo construto, a autora faz a divisão da intimidade como consumidor $\mathbf{x}$ marca e marca $\mathbf{x}$ consumidor. A primeira parte da variável considera basicamente o conhecimento da marca pelo consumidor. Já a segunda faz suposições sobre o cuidado da marca em relação ao consumidor. Apesar do índice de confiabilidade destas duas partes serem interessantes (alpha acima de 0,80 ), não há sustentação teórica sobre o motivo da separação dos indicadores. De acordo com as definições conceituais acerca da intimidade com a marca (Fournier, 1998; Ribeiro et al., 2010), o conteúdo desta variável está mais próximo de caracterizar uma situação bidimensional, como o caso tratado neste estudo. Atenta-se ao fato que a variável interdependência com a marca houve uma modificação na estrutura de medida. Por questões de ajuste da escala, sem perda de significado mensurado, o item 1 foi suprimido da etapa final de análise, tendo em vista que o peso padronizado dos demais indicadores na CFA foi maior para os itens que permaneceram na escala

Na sequência, a Tabela 5 trata do resumo obtido da verificação das proposições de pesquisa, resultantes da CFA de segunda ordem. De acordo com os dados, percebe-se que cada variável, de fato, reflete parte do BRQ. Os índices de ajuste do modelo foram aceitáveis: CMIN/DF 2,189, NFI = 0,888, $\mathrm{RFI}=0,878, \mathrm{IFI}=0,936, \mathrm{TLI}=0,930, \mathrm{CFI}=0,935$ e RMSEA $=0,048$. Em especial, a intimidade com 
a marca $\left(\beta=0,893, p<0,001\right.$ e $\left.\mathrm{R}^{2}=79,74 \%\right)$ corresponde ao maior poder de reflexão sobre o BRQ, seguida pela autoconexão com a marca $\left(\beta=0,857, \mathrm{p}<0,001\right.$ e $\left.\mathrm{R}^{2}=73,44 \%\right)$ e pelo comprometimento com a marca $\left(\beta=0,807, p<0,001\right.$ e $\left.R^{2}=65,12 \%\right)$. Apesar da menor contribuição, interdependência com a marca $\left(\beta=0,760, p<0,001\right.$ e $\left.R^{2}=57,76 \%\right)$, senso de parceira com a marca $\left(\beta=0,581, p<0,001\right.$ e $R^{2}=$ $33,75 \%)$ e a manifestação do amor/paixão pela marca $\left(\beta=0,375, \mathrm{p}<0,001\right.$ e $\left.\mathrm{R}^{2}=14,06 \%\right)$, também, são significativos.

Supõe-se que, mesmo com a verificação do modelo, possa haver a interferência da avaliação em relação às categorias avaliadas e à multiplicidade de marcas, conforme já comentado. Recorda-se que a variável sobre amor/paixão foi a que registrou menores médias (indicando discordância sobre o sentimento forte e positivo demonstrado por algumas marcas). No entanto Ahuvia (2005) demonstrou a relevância da manifestação de objetos e marcas amadas pelo consumidor em estudo anterior tendo em vista outras categorias de produto. Também Schouten e McAlexander (1995) relataram o apego dos new bikes seguido do amor pela marca tendo em vista a fusão do estilo de vida, crença e valores dos indivíduos e da marca. A motocicleta (produto físico) e a marca (símbolo intangível), após um tempo, passam a ser extensões da pessoa, portanto, é natural o carinho, apego e amor pelos bens possuídos. Ressalta-se que esta manifestação não é, necessariamente, linear e instantânea, desse modo, a demonstração de maior afeto por uma marca pode depender de outros fatores como a experiência, a especificidade da marca, questões de gênero ou até mesmo de categorias de produto.

Tabela 5

\section{Proposições de Pesquisa}

\begin{tabular}{lcccc}
\hline Variável & Proposição & Loading & Sig & $\mathbf{R}^{\mathbf{2}}$ \\
\hline $\mathrm{BRQ} \rightarrow$ Amor/paixão pela marca & 1 & 0,375 & 0,000 & $14,0 \%$ \\
$\mathrm{BRQ} \rightarrow$ Autoconexão com a marca & 2 & 0,857 & 0,000 & $73,4 \%$ \\
$\mathrm{BRQ} \rightarrow$ Comprometimento com a marca & 3 & 0,807 & 0,000 & $65,1 \%$ \\
$\mathrm{BRQ} \rightarrow$ Interdependência com a marca & 4 & 0,760 & 0,000 & $57,7 \%$ \\
$\mathrm{BRQ} \rightarrow$ Parceria/Confiança na marca & 5 & 0,581 & 0,000 & $33,7 \%$ \\
$\mathrm{BRQ} \rightarrow$ Intimidade com a marca & 6 & 0,893 & 0,000 & $79,7 \%$ \\
\hline
\end{tabular}

Nota. Fonte: Resultado da Pesquisa.

Esta primeira etapa empírica responde aos objetivos específicos designados na introdução como a e b. Assim, como síntese dos resultados, tem-se que a análise conjunta das escalas propostas neste estudo, de fato, mostra-se capaz de mensurar o BRQ enquanto variável latente. E implica em considerar que o modelo de mensuração tem característica refletiva, mas com diferentes cargas fatoriais sobre cada variável. Portanto a qualidade do relacionamento com a marca está associada principalmente à percepção de conexão das características pessoais do indivíduo com a marca, do conhecimento do senso de reciprocidade e do comprometimento na relação.

\section{Teste do modelo proposto}

De acordo com o terceiro objetivo específico deste estudo, o modelo que verifica a relação do BRQ sobre a lealdade é testado por meio de modelagem estrutural e segue ilustrado na Figura 2. O modelo final considera uma estrutura de terceira ordem tendo em vista que os construtos de intimidade e autoconexão são bidimensionais. $\mathrm{O}$ ajuste geral do modelo foi: $\mathrm{CMIN} / \mathrm{DF} 2,304, \mathrm{NFI}=0,864, \mathrm{RFI}=$ $0,854, \mathrm{IFI}=0,918, \mathrm{TLI}=0,912, \mathrm{CFI}=0,918$ e RMSEA $=0,051$. O poder de explicação do BRQ sobre a lealdade foi registrado em $43,3 \%$. Também os índices de AVE $(0,54)$ e a Confiabilidade composta $(0,87)$ do BRQ são considerados adequados.

Conforme observado no modelo e nos índices de ajuste, a hipótese testada via modelagem 
estrutural refere-se ao impacto do BRQ sobre a lealdade do indivíduo, de acordo com a hipótese 1. Por conseguinte é comprovado o impacto positivo e significativo do BRQ sobre a lealdade manifestada pelo respondente $(\beta=0,658, \mathrm{p}<0,001)$.

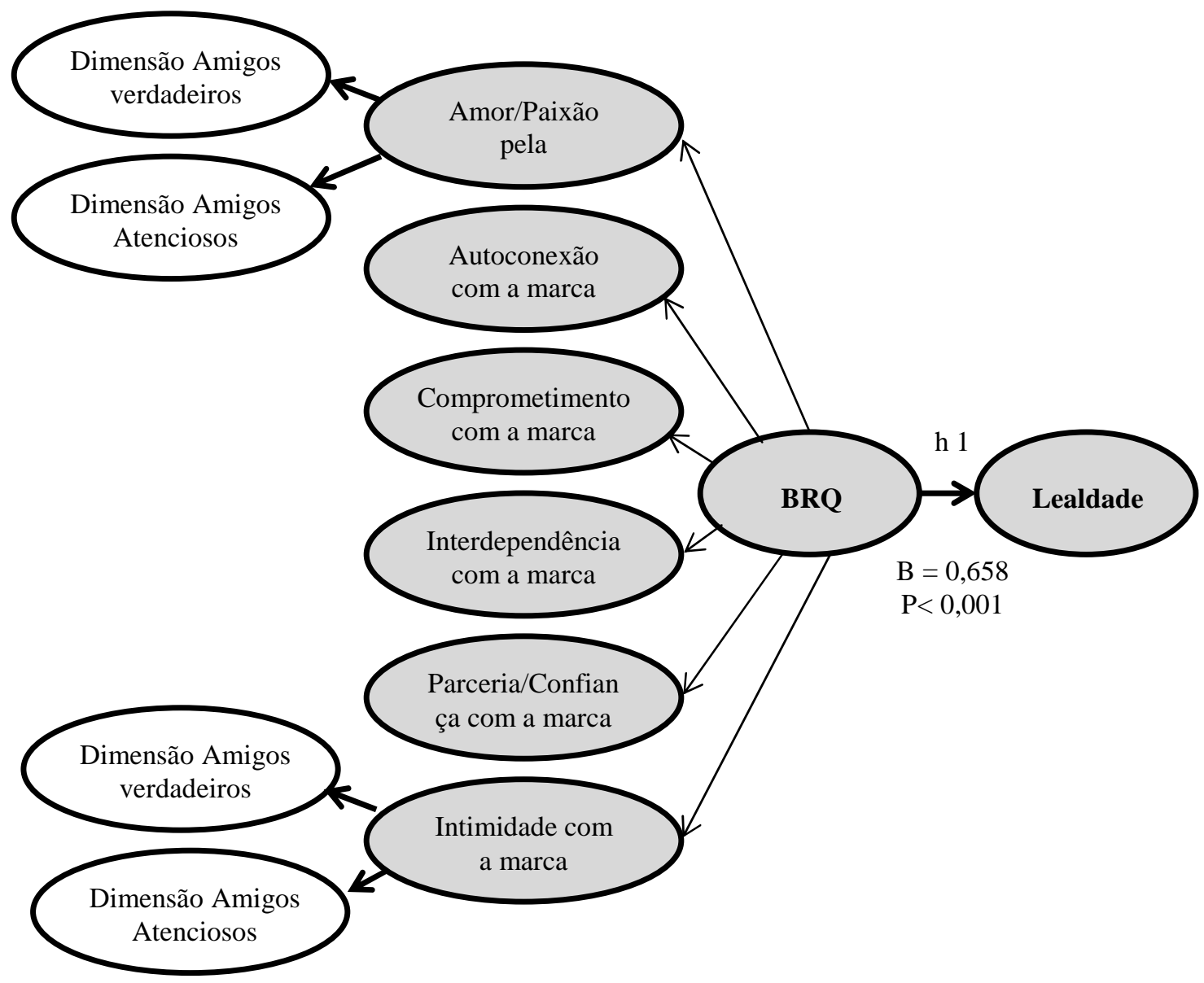

Figura 2. Modelo Completo BRQ e o Impacto na Lealdade.

Fonte: Resultado da Pesquisa.

No entanto, ao verificar o poder de explicação da relação $\left(\mathrm{R}^{2} 43 \%\right)$, indaga-se sobre possíveis efeitos na amostra que podem minimizar o impacto percebido.

Desta forma, o modelo proposto foi comparado tendo em vista o cruzamento de 2 variáveis categóricas: gênero e categoria de produtos, como ilustra a Tabela 6. Conforme Byrne (2001), a diferença de $\chi^{2}$ indica a presença de diferença nas comparações testadas. $O$ teste considera a comparação de dois modelos, sento um com parâmetro livre e outro indicando igualdade.

Tabela 6

Diferenças por Gênero e Categoria de Produto

\begin{tabular}{|c|c|c|c|c|c|c|c|c|c|c|c|c|}
\hline MODELO & $\mathbf{X}^{2}$ & df & $\Delta \mathbf{X}^{2}$ & $\Delta \mathbf{d f}$ & Sig & NFI & RFI & IFI & TLI & CFI & RMSEA & $\begin{array}{c}\text { BRQ - } \\
\text { LEALDADE }\end{array}$ \\
\hline Livre (H/M) & 2275,7 & 1310 & 4,7 & 1 & $<0,05$ & 0,804 & 0,79 & 0,907 & 0,899 & 0,906 & 0,039 & $\begin{array}{c}\mathrm{M}=0,708^{*} / \\
\mathrm{H}=0,591 *\end{array}$ \\
\hline $\begin{array}{l}\text { Igualdade } \\
(\mathrm{H} / \mathrm{M})\end{array}$ & 2280,4 & 1311 & & & U, & 0,804 & 0,79 & 0,906 & 0,898 & 0,905 & 0,039 & $\begin{array}{c}\mathrm{M}=0,684 * / \\
\mathrm{H}=0,626 *\end{array}$ \\
\hline
\end{tabular}


Tabela 6 (continuação)

\begin{tabular}{|c|c|c|c|c|c|c|c|c|c|c|c|c|}
\hline MODELO & $\mathbf{X}^{2}$ & df & $\Delta \mathbf{X}^{2}$ & $\Delta \mathbf{d f}$ & Sig & NFI & RFI & IFI & TLI & CFI & RMSEA & $\begin{array}{c}\text { BRQ - } \\
\text { LEALDADE }\end{array}$ \\
\hline Livre $(\mathrm{C} / \mathrm{T})$ & 2402,1 & 1310 & \multirow[t]{2}{*}{3,2} & \multirow[t]{2}{*}{1} & \multirow[t]{2}{*}{$<0,05$} & 0,801 & 0,786 & 0,899 & 0,89 & 0,898 & 0,041 & $\begin{array}{c}\mathrm{C}=0,612 * / \\
\mathrm{T}=0,683^{*}\end{array}$ \\
\hline $\begin{array}{l}\text { Igualdade } \\
(\mathrm{C} / \mathrm{T})\end{array}$ & 2405,3 & 1311 & & & & 0,801 & 0,786 & 0,898 & 0,89 & 0,897 & 0,041 & $\begin{array}{c}\mathrm{C}=0,641^{*} / \\
\mathrm{T}=0,665^{*}\end{array}$ \\
\hline $\begin{array}{l}\text { Livre } \\
(\mathrm{MJ} / \mathrm{HJ})\end{array}$ & 2052,6 & 1310 & \multirow{2}{*}{1,9} & \multirow{2}{*}{1} & \multirow{2}{*}{$<0,05$} & 0,652 & 0,626 & 0,838 & 0,822 & 0,835 & 0,054 & $\begin{array}{c}\mathrm{MJ}=0,498 * / \\
\mathrm{HJ}=0,658 *\end{array}$ \\
\hline $\begin{array}{l}\text { Igualdade } \\
\text { (MJ/HJ) }\end{array}$ & 2054,5 & 1311 & & & & 0,652 & 0,626 & 0,838 & 0,822 & 0,834 & 0,054 & $\begin{array}{c}\mathrm{MJ}=0,386^{*} / \\
\mathrm{HJ}=0,677^{*}\end{array}$ \\
\hline $\begin{array}{l}\text { Livre } \\
(\mathrm{MT} / \mathrm{HT})\end{array}$ & 2214,6 & 1310 & \multirow{2}{*}{0,8} & \multirow{2}{*}{1} & \multirow{2}{*}{$<0,05$} & 0,721 & 0,701 & 0,864 & 0,852 & 0,862 & 0,048 & $\begin{array}{c}\mathrm{MT}=0,758 * / \\
\mathrm{HT}=0,536 *\end{array}$ \\
\hline $\begin{array}{l}\text { Igualdade } \\
\text { (MT/HT) }\end{array}$ & 2215,4 & 1311 & & & & 0,721 & 0,701 & 0,864 & 0,852 & 0,862 & 0,048 & $\begin{aligned} \mathrm{MT} & =0,751^{*} / \\
\mathrm{HT} & =0,565^{*}\end{aligned}$ \\
\hline $\begin{array}{l}\text { Livre } \\
\text { (MT/MJ) }\end{array}$ & 2160,1 & 1310 & \multirow{2}{*}{0,1} & \multirow[t]{2}{*}{1} & \multirow{2}{*}{$<0,05$} & 0,709 & 0,688 & 0,861 & 0,848 & 0,859 & 0,049 & $\begin{array}{c}\mathrm{MT}=0,758 * / \\
\mathrm{MJ}=0,498 *\end{array}$ \\
\hline $\begin{array}{l}\text { Igualdade } \\
\text { (MT/MJ) }\end{array}$ & 2160,2 & 1311 & & & & 0,709 & 0,688 & 0,861 & 0,849 & 0,859 & 0,049 & $\begin{array}{c}\mathrm{MT}=0,756^{*} / \\
\mathrm{MJ}=0,514^{*}\end{array}$ \\
\hline $\begin{array}{l}\text { Livre } \\
(\mathrm{HT} / \mathrm{HJ})\end{array}$ & 2108,2 & 1310 & \multirow{2}{*}{1,6} & \multirow[t]{2}{*}{1} & \multirow[t]{2}{*}{$<0,05$} & 0,672 & 0,648 & 0,844 & 0,829 & 0,841 & 0,052 & $\begin{array}{c}\mathrm{HT}=0,536^{*} / \\
\mathrm{HJ}=0,658^{*}\end{array}$ \\
\hline $\begin{array}{l}\text { Igualdade } \\
(\mathrm{HT} / \mathrm{HJ})\end{array}$ & 2109,8 & 1311 & & & & 0,672 & 0,648 & 0,844 & 0,829 & 0,841 & 0,052 & $\begin{array}{c}\mathrm{HT}=0,478 * / \\
\mathrm{HJ}=0,681 *\end{array}$ \\
\hline
\end{tabular}

Nota. Tamanho de amostra: HT=101 / HJ=130/ H=231/ T=310 /MT=199 / MJ=68 / M=277/ J=198. Legenda: H=Homem / M=Mulher / J=Jeans / T=Tênis $* \operatorname{Sig}<0,05$

Ao comparar o resultado dos grupos comparados, dois a dois, inicialmente, percebe-se que o modelo estrutural proposto é robusto o suficiente para apresentar relações significativas em todos os grupos, afinal, em todos os modelos, a hipótese de pesquisa é significativa. Entretanto ressalta-se que existe uma discrepância entre o tamanho das amostras à medida que os grupos são comparados. Tal fato sugere certo viés na comparação dos betas livres e com igualdade. Desta forma, não foi possível verificar diferenças na interação entre gênero e categoria de produto. Tal discrepância na amostra pode também ter influenciado os índices de ajuste.

De acordo com a análise da significância da diferença do $\chi 2$ para 1 grau de liberdade e intervalo de confiança de $95 \%$, verifica-se que há diferença significativa na comparação entre homens e mulheres $\left(\Delta \chi^{2}>3,841\right)$. Há também diferença quanto à categoria de produto, considerando confiança de $90 \%\left(\Delta \chi^{2}>2,706\right)$. Assim, observa-se que a relação entre a qualidade do relacionamento com marca e a lealdade tende a ser significativamente mais forte entre as mulheres $(\beta=0,708)$ do que entre homens $(\beta=0,591)$. Quanto à categoria de produto, o tênis esportivo $(\beta=0,683)$ parece ser mais relevante do que a categoria de jeans $(\beta=0,612)$. O estudo de Francisco-Maffezzolli et al. (2008) relatou, por meio de campo empírico qualitativo, a relação de proximidade e importância da marca Nike como tênis em atinência a atividades rotineiras para uma consumidora assídua deste produto/marca para alguns consumidores, fato que sugere uma relação mais próxima do consumidor com esta categoria de produto. Além disso, cabe ressaltar que estudos anteriores (Breivik \& Thorjornsen, 2008) demonstram valores maiores do impacto do BRQ sobre a propensão de recomendar e comprar novamente, mas tendo utilizado produtos de alto envolvimento (exemplo: bens de tecnologia).

Sobre a diferença de gênero observada nos resultados deste estudo, recorda-se que a proposta fenomenológica de Fournier (1998) considerou o estudo com 3 mulheres, já que a consumidora feminina poderia estar mais disposta a mostrar e compartilhar sua rotina com a presença de certas marcas, nas palavras da autora. Ademais, a autora também comenta sobre a maior facilidade feminina 
para a externalização de sensações afetivas, fato importante para a conclusão do estudo da referida autora.

Sendo assim, sugere-se que o BRQ é um modelo sensível às características de gênero e de categoria de produto, portanto deve ser empregado em situações que desejem controlar tais diferenças. Acredita-se que produtos e marcas que estimulem a função e valorização predominantemente hedônica tenham maior desempenho no BRQ. Do contrário, produtos e marcas com função e valorização mais utilitárias não carecem de um modelo tão robusto, como o caso de Francisco (2007) e Prado (2004).

\section{Discussão dos resultados}

De acordo com os objetivos especificados na introdução, tem-se que a primeira contribuição original a este estudo foi a proposição e validação do modelo de mensuração do BRQ no contexto brasileiro, segundo a proposta conceitual de Fournier (1998).

Estudos anteriores, como de Fournier (2000 como citado em Fournier 2009), Thorbjornsen, Supphellen, Nysveen e Egil (2002), Kim, Lee e Lee (2005), Zhimin (2007), Breivik e Thorbjornsen (2008), demonstraram significativos avanços nesta área do conhecimento, porém com situações e gaps específicos. Os estudos de Fournier (2009) detectaram uma tentativa de mensuração em contexto de produtos tangíveis, mas a autora encontrou limitações na validação da escala, segundo a origem conceitual dos construtos analisados, conforme apresentado no item Avaliação do modelo de mensuração deste estudo. Thorbjornsen et al. (2002) fizeram uma avaliação em contexto virtual, fato bem original ao estudo dos autores, porém com certa limitação quanto ao uso das seis variáveis latentes de origem do BRQ. Os autores não mensuraram no modelo variáveis importantes como a intimidade com a marca. Kim et al. (2005) elaboram uma escala na qual são considerados 5 itens, sendo eles: autoconexão, satisfação, comprometimento, confiança e intimidade com a marca. Percebese que, neste modelo, há uma mudança conceitual da proposta de Fournier (1998). Zhimin (2007) desenvolve uma escala para o contexto chinês que, no final, tem o objetivo de criar um escore de comparação entre as marcas. Portanto, há uma alteração na concepção nomológica do construto. Para este autor a estrutura do BRQ é formativa.

O estudo de Breivik e Thorbjornsen (2008) sugere uma série de comparativos sobre a qualidade do BRQ e da Qualidade do Relacionamento na busca do modelo que melhor consegue explicar o fenômeno do relacionamento, mas como predominância do contexto norte-americano. Além da discussão acerca da composição do modelo, seguindo a proposta original de Fournier (1998), também, o presente estudo propiciou a reflexão sobre a estrutura nomológica do modelo e valida a composição refletiva do modelo. Tal condição, igualmente, foi evidenciada nos estudos de Breivik e Thorjornsen (2008) e foi contemplada no segundo objetivo deste estudo. Isto implica em reconhecer que é coerente avaliar o BRQ por meio do modelo de mensuração proposto neste estudo.

Já o impacto do BRQ sobre a lealdade, apontado como terceiro objetivo deste estudo, foi testado e comprovado via modelagem estrutural. O fato original deste estudo, neste aspecto, está apoiado nos contrastes feitos entre gêneros e categorias de produto. As implicações deste resultado assinalam a dependência do contexto de análise. Por conseguinte sugere-se que o significado compartilhado e valorizado entre o consumidor e seu meio social acerca da marca consumida favorece o fortalecimento da avaliação do BRQ. Mulheres tendem a ser mais sensíveis a questões de valoração simbólica, dependendo da categoria de produtos.

\section{Considerações Finais}

O presente estudo está apoiado em três principais contribuições acerca do modelo de mensuração do BRQ e da sua relação com a lealdade. A primeira ressalta a proposição do modelo de $\mathrm{BRQ}$, que parece de forma global mais ajustado, robusto e fiel às particularidades conceituais de cada 
uma das seis variáveis latentes analisadas. A segunda trata da comprovação empírica do BRQ enquanto variável latente de terceira ordem. Esta estrutura permite perceber a presença predominante do senso de conexão com a marca como elemento de identificação e compartilhamento de valores simbólicos da marca. Também o senso de reciprocidade e o comprometimento afetivo revelam partes importantes do BRQ. E isso implica no reforço de aspectos emocionais, cognitivos e comportamentais na comunicação e promoção da marca, quando o objetivo desta é oferecer subsídios para estimular uma relação forte com o consumidor.

Em terceiro, ressalta-se a contribuição do BRQ como elemento de impacto sobre a lealdade. Comparando o modelo geral com os grupos gerados, percebe-se que o coeficiente de determinação sofre interferência de características como gênero e categoria de produtos. E, assim, implica que nem todas as pessoas veem o relacionamento com marcas consumidas da mesma forma. Sendo assim, gestores de marketing não deveriam tratar os consumidores da mesma forma. Identificar o consumidor foco das ações de marketing é fundamental para o êxito nas ações promocionais. Por exemplo, uma vez reconhecido que, na loja de artigos esportivos, o tênis esportivo tem um aspecto simbólico mais relevante para o público feminino, ações que intensifiquem esta percepção e que gerem identificação com o público parecem mais assertivas do que fazer uma comunicação com apelo genérico.

Ademais, além da segmentação de acordo com variáveis sociodemográficas, também, é possível fazer um filtro secundário de acordo com a relação consumidor versus marca. Por exemplo, pessoas com maior propensão a sentirem-se conectadas a uma marca, tendo em vista benefícios funcionais e simbólicos que esta proporcione, não deveriam receber o mesmo tratamento que pessoas que compram a marca por inércia ou acaso. Sugere-se o uso de programas de incentivo, como o tratamento de cliente especial. Afinal, tendo em vista que o relacionamento é uma via de mão dupla, a qualidade do relacionamento com marca é também fruto da concepção recíproca de: gosto da marca porque ela gosta de mim.

\section{Limitações do Estudo e Futuras Pesquisas}

Este estudo apresenta limitações quanto à escolha do contexto de pesquisa (tênis esportivo e calça jeans) e abrangência da amostra. Sugere-se que estudos futuros possam testar diferentes composições acerca destes dois itens. Sabe-se que cada estrutura de pesquisa é decorrente das escolhas empregadas nos procedimentos metodológicos. Neste caso, o estudo cross sectional empregado, apesar de coerente com a forma de análise proposta, permite uma análise limitada da relação entre consumidor x marca. Desta forma, em consonância ao estudo de Fournier (2009), sugere-se que o teste de estruturas mais dinâmicas de relacionamento seja empregado. Estudos longitudinais poderiam promover tal observação. Ressalta-se ainda a limitação sobre a mensuração da profundidade das percepções no tocante ao relacionamento com marca. Estudos qualitativos podem suprir este gap, bem como elucidar as motivações e aspirações dos consumidores. Também a escolha de respondentes entre 18 e 30 anos demonstra um recorte limitado do ciclo de vida. Francisco-Maffezzolli (2010) destaca, em estudo qualitativo, a diferença de relação com marca de acordo com o estágio do ciclo de vida, bem como da função social que a pessoa é responsável. Portanto elementos de uso pessoal podem ser mais relevantes à pessoas mais jovens, já produtos que indicam o cuidado da casa podem ser mais importantes para pessoas responsáveis pelo lar. Tais diferenças podem ser testadas e validadas em estudos futuros. Ainda outras limitações com relação à amostragem utilizada refere-se à delimitação geográfica do estudo, universidades de Curitiba, o que não fornece capacidade generalizadora dos resultados. A comparação entre classes sociais seria também uma possibilidade para futuras pesquisas. 


\section{Referências}

Ahuvia, A. C. (2005). Beyond the extended self: loved objects and consumers' identity narratives. Journal of consumer research, 32(1), 171-184. doi: 10.1086/429607

Anderson, J. C., \& Gerbing, D. W. (1988). Structural equation modeling in practice: a review and recommended two-step approach. Psychological Bulletin, 103(3), 411-423. doi: 10.1037//00332909.103.3.411

Ashworth, L., Dacin, P., \& Thomson, M. (2009). Why on earth do consumers have relationships with marketers? Toward understanding the functions of brand relationships. In D. J. Macinnis, C. W. Park, \& J. R. Priester (Eds.), Handbook of brand relationships (pp. 82-106). New York: M.E. Sharpe, Inc.

Barnes, J. G. (2002). Segredos da gestão pelo relacionamento com os clientes-CRM. Rio de Janeiro: Qualitymark.

Bisbe, J., Batista-Foguet, J.-M., \& Chenhall, R. (2007). Defining management accounting constructs: a methodological note on the risks of conceptual misspecification. Accounting, Organizations and Society, 32(7-8), 789-820. doi: 10.1016/j.aos.2006.09.010

Breivik, E., \& Thorbjornsen, H. (2008). Consumer brand relationships: an investigation of two alternative models. Journal of the Academy Marketing Science, 36(4), 443-472. doi: $10.1007 / \mathrm{s} 11747-008-0115-\mathrm{z}$

Byrne, B. M. (2001). Structural equation modeling with amos: basic concepts, applications and programming. Mahwah, USA: LEA.

Carvalho-Freitas, M. N., \& Marques, A. L. (2010). Formas de ver as pessoas com deficiência: um estudo epírico de construto de concepções de deficiência em situações de trabalho. Revista de Administração da Mackenzie, 11(3), 100-129. doi: 10.1590/S1678-69712010000300007

Churchill, G. A. (1987). Marketing research: methodological foundations. Chicago, USA: Dryden.

Escalas, J. E., \& Bettman, J. R. (2009). Self-brand connections: the role of reference groups and celebrity endorsers in the creation of brand meaning. In D. J. Macinnis, C. W. Park, J. R. Priester (Eds.), Handbook of brand relationships (pp. 107-123). New York: M.E. Sharpe, Inc.

Fornell, A. (1992). National customer satisfaction barometer: the swedish experience. Journal of Marketing, 56(1), 6-21.

Fornell, C., \& Larcker, D. F. (1981). Evaluating structural equation models with unobservable variables and measurement error. Journal of Marketing Research, 18(1), 39-50. doi: $10.2307 / 3151312$

Fournier, S. (1998). Consumers and their brands: developing relationship theory in consumer research. Journal of Consumer Research, 24(4), 343-353. doi: 10.1086/209515

Fournier, S. (2009). Lessons learned about consumers' relationships with their brands. In D. J. Macinnis, C. W. Park, J. R. Priester (Eds.), Handbook of brand relationships (pp. 5-23). New York: M.E. Sharpe, Inc.

Francisco, E. C. (2007). Impacto da lealdade e da qualidade do relacionamento no resultado financeiro dos clientes: estudo no setor de telefonia celular (Dissertação de Mestrado). Universidade Federal do Paraná, Curitiba, PR, Brasil. 
Francisco-Maffezzolli, E. C. (2010). Proposta de um modelo de CBBE - customer based brand equity. (Tese de Doutorado). Universidade federal do Paraná, Curitiba, PR, Brasil.

Francisco-Maffezzolli, E. C., Mady, E. B., Brunetta, D., Lima, M. V. V., Fabris, C., \& Santos, T. (2008, maio). Um modelo conceitual das relações entre sentimentos, intimidade, interdependência e autoconexão do consumidor com marcas. Anais do Encontro de Marketing, Curitiba, PR, Brasil, 3.

Francisco-Maffezzolli, E. C., Prado, P. H. M., \& Montaña, J. (2010). Building the brand identification concept [Working paper]. Annual Conference of the Special Interest Group on Brand, Identity and Corporate Reputation of the Academy of Marketing, Barcelona, Spain, 6.

Frijda, N. H., Manstead, A. S. R., \& Bem, S. (2000). Emotions and beliefs: how feelings influence thoughts. Paris: Cambridge University Press.

Garbarino, E., \& Johnson, M. S. (1999). The different roles of satisfaction, trust, and commitment in customer relationships. Journal of Marketing, 63(2), 70-87. doi: 10.2307/1251946

Goodstein, L. D., \& Butz, H. E. (1998). Customer value: the linchpin of organizational change. Organizational Dynamics, 27(1), 21-34. doi: 10.1016/S0090-2616(98)90038-9

Grönroos, C. (1990). Relationship approach to the marketing function in service contexts: the marketing and organizational behavior interface. Journal of Business Research, 20(1), 3-11.

Grönroos, C. (1997). Keynote paper from marketing mix to relationship marketing - towards a paradigm shift in marketing. Management Decision, 35(4), 322-339. doi: $10.1108 / 00251749710169729$

Hair, J. F., Anderson, R. E., Tatham, R. L., \& Black, W. C. (2005). Análise multivariada de dados (5th ed.). Porto Alegre: Bookman.

Hazan, C., \& Shaver P. R. (1994). Attachment as an organizational framework for research on close relationships. Psychological Inquiry, 5(1), 1-22. doi: 10.2307/1449075

Jones, O. T., \& Sasser, W. E. (1995). Why satisfied customers defect. Harvard Business Review, 73(6), 88-89.

Kapferer, J. N. (2003). As marcas: capital da empresa (3a ed.). Porto Alegre: Bookman.

Keller, K. L., \& Machado, M. (2006). Gestão estratégica de marcas. São Paulo: Pearson Education.

Kim, H. K., Lee, M., \& Lee, Y. M. (2005). Developing a scale for measuring brand relationship quality. Asia Pacific Advances in Consumer Research, 6(1), 118-126.

Mackinnis, D. J., Park, C. W., \& Priester, J. R. (2009). Handbook of brand relationships. London, England: M. E. Sharpe.

Malhotra, N. K. (2006). Pesquisa de marketing: uma orientação aplicada (4a ed.). Porto Alegre: Bookman.

Malhotra, N. K. (2012). Pesquisa de marketing: uma orientação aplicada (6a ed.). Porto Alegre: Bookman.

Morgan, R. M., \& Hunt, S. D. (1994). The commitment-trust theory of relationship marketing. Journal of Marketing, 58(3), 20-38. doi: 10.2307/1252308

Oliver, R. L. (1981). Measurement and evaluation of satisfaction process in retail settings. Journal of Retailing, 57(3), 25-48. 
Oliver, R. L. (1999). Whence consumer loyalty? [Special Issue]. Journal of Marketing, 63, 33-44. doi: $10.2307 / 1252099$

Pallant, J. (2001). SPSS survival manual. Philadelphia: Open University Press.

Park, C. W., Macinnis, D. J., \& Priester, J. R. (2009). Research directions on strong brand relationships. In D. J. Macinnis, C. W. Park, \& J. R. Priester (Eds.), Handbook of brand relationships (pp. 379-393). New York: M.E. Sharpe, Inc.

Prado, P. H. M. (2004). A avaliação do relacionamento sob a ótica do cliente: um estudo em bancos de varejo (Tese de Doutorado). Fundação Getúlio Vargas, São Paulo, SP, Brasil.

Prado, P. H. M., Lima, M. V. V., Santos, T., Francisco-Maffezzolli, E. C., Semprebom, E., \& Ribeiro, C. M. (2009, setembro). A relação de interdependência do consumidor com marca - o desenvolvimento de uma escala de mensuração. Anais do Encontro Nacional da Associação Nacional de Pós-Graduação e Pesquisa em Administração, São Paulo, SP, Brasil, 33.

Reimann, M., \& Aron, A. (2009). Self-expansion motivation and inclusion of brands in self: toward a theory of brand relationships. In D. J. Macinnis, C. W. Park, \& J. R. Priester (Eds.), Handbook of brand relationships (pp. 65-81). New York: M.E. Sharpe, Inc.

Ribeiro, C. M., Semprebom, E., Francisco-Maffezzolli, E. C., Fabris, C., Prado, P. H. M., \& Santos, T. (2010, setembro). Afinal, temos um relacionamento íntimo? Anais do Encontro Nacional da Associação Nacional de Pós-Graduação e Pesquisa em Administração, Rio de Janeiro, RJ, Brasil, 34.

Rusbult, C. E., \& Arriaga, X. B. (1997). Interdependence theory. In S. Duck (Ed.), Handbook of personal relationship: theory, research and interventions (2nd ed., pp. 147-150). Londres: John Wiley \& Sons.

Schouten, J. W., \& McAlexander, J. H. (1995). Subcultures of consumption: an ethnography of the new bikers. Journal of Consumer Research, 22(1), 43-61. doi: 10.1086/209434

Tam, L., Wood, W., \& Ji, M. F. (2009). Brand loyalty is not habitual. In D. J. Macinnis, C. W. Park, \& J. R. Priester (Eds.), Handbook of brand relationships (pp. 43-62). New York: M.E. Sharpe, Inc.

Thibault, J. W., \& Kelley, H. H. (1959). The social psychology of groups. New York, NY: Wiley.

Thorbjornsen, H., Supphellen, M., Nysveen, H., \& Egil, P. (2002). Building brand relationships online: a comparative of two interactive applications. Journal of Interactive Marketing, 16(3), 17-37. doi: 10.1002/dir.10034

Tildesley, A. E., \& Coote, L. V. (2009). This brand is me: a social identity based measure of brand identification. Advances in Consumer Research, 36(1), 627-628.

Vala, J., \& Monteiro, M. B. (2004). Psicologia social. Lisboa: Fundação Calouste Gulbenkian.

Wilson, D. T. (1995). An integrated model of buyer-seller relationships. Journal of Academy Marketing Science, 23(4), 335-345. doi: 10.1177/009207039502300414

Yi, Y., \& Jeon, H. (2003). Effects of loyalty programs on value perception, program loyalty, and brand loyalty. Journal of Academic Marketing Science, 31(3), 229-240. doi: $10.1177 / 0092070303031003002$

Zeithaml, V. A. (1988). Consumer perceptions of price, quality, and value: a means-end model and synthesis of evidence. Journal of Marketing, 52(3), 2-22. doi: 10.2307/1251446

Zhimin, Z. (2007). How to measure brand relationship quality? Business Research China, 1(2), 300318. doi: 10.1007/s11782-007-0017-9 